\title{
A Mutant Form of Ornithine Transcarbamylase Found in a Strain of Neurospora Carrying a Pyrimidine-Proline Suppressor Gene ${ }^{1}$
}

\author{
ROWLAND H. DAVIS
}

\author{
From the Department of Botany, University of Michigan, Ann Arbor, Michigan
}

Received November 2, 1961

\begin{abstract}
A mutation, $s$, of Neurospora, leads to a $98 \%$ reduction in ornithine transcarbamylase (OTC) activity without imposing an arginine requirement. It has been found that the enzyme present in the $s$ strain is different from the normal enzyme in its affinities for ornithine and carbamyl phosphate. The affinity of the mutant enzyme for carbamyl phosphate is much greater than in the case of the wild type enzyme, and this characteristic could compensate to a large extent for the low specific activity in $s$ strains. The data are used to indicate that the $s$ locus is a gene which controls the structure of OTC in Neurospora. The possibility of there being two forms of this enzyme in wild type strains is discussed.
\end{abstract}

\section{INTRODUCTION}

A mutation, designated $s$ ("supprcssor"), which eliminates the nutritional requirement of certain pyrimidine and proline mutants of Neurospora, has been described previously (1-3). Strains carrying $s$ in an otherwise wild type genome are almost impossible to distinguish from wild type on nutritional criteria. Since a pyrimidine requirement could be restored to suppressed pyr 3 mutants by the addition of arginine to the medium, it was felt that these pyr 3 mutants were fundamentally arginine-sensitive [however, see Ref. (3)], and that the $s$ mutation led to an impairment of endogenous arginine synthesis. It was subsequently found that the $s$ mutation imposed a reduction of $98 \%$ in the specific activity of the enzyme ornithine transcarbamylase (OTC) $(2,3)$, which catalyzes the formation of citrulline from ornithine and carbamyl phosphate (CAP) with the liberation of inorganic phosphate. Free arginine, derived from citrulline, was found to be greatly reduced in its concentration in growing my-

\footnotetext{
${ }^{1}$ Supported in part by an Institutional Research Grant to the University of Michigan from the American Cancer Society and by a grant (G18012) from the National Science Foundation.
}

celia of the $s$ strain in comparison to wild type (3). The effect of $s$ on proline mutants can be understood hypothetically in terms of a reduced utilization of glutamic- $\gamma$-semialdehyde, a precursor common to arginine and proline synthesis in Neurospora.

The magnitude of the effect of the $s$ gene on O'TC activity made the absence of a significant arginine requirement in such strains curious. The properties of OTC from mutant and wild type were studied, therefore, to determine whether the enzyme from the mutant was a more efficient catalyst. Another purpose of these studies was to obtain evidence to show whether or not the $s$ locus was the primary determinant of OTC in Neurospora, since two arginine mutants blocked between ornithine and citrulline nutritionally were shown to have normal or high activities for this cnzyme (3).

\section{MATERIALS}

'The strains of Neurospora crassa used were a wild type isolate and an isolate which carried the $s$ gene; they will be referred to as wild type and $s$, respectively. These two strains were taken from the same ascus of a cross between wild type $1 A$ and the suppressed pyr $3 a$ mutant, 37301 \& [isolates $7 c$ and $7 d$; cf. Ref. (3)]. Mycelia were grown in 700 
$\mathrm{ml}$. media in low-form culture flasks on a reciprocal shaker for $24 \mathrm{hr}$. The growth was harvested, dried in acetone, ground in acetone to a fine powder, and dried in air (3). This powder was used as the source of OTC in all enzyme work unless otherwise indicated.

L-Ornithine dihydrochloride (Nutritional Biochemicals Corp.) or L-ornithine monohydrochloride (Sigma Chemical Co.) was used in all enzyme work. Carbamyl phosphate (dilithium salt) was prepared by the method of Spector, Jones, and Lipmann (4), but with special attention to drying it quickly in the final stage of preparation. This was done by collecting the reprecipitated CAP in a Büchner funnel, and pressing it as dry as possible with a spatula. Cold $95 \%$ ethanol was poured over the sediment, the ethanol was drawn through it, and, while aspiration continued, the CAP was slowly scraped off the top of the mass with a spatula as it dried. The resulting particles were then placed in a moving air stream until the ethanol odor was gone, and the particles were broken to a fine powder. The powder was stored over phosphorus pentoxide at room temperature, where it remained stable for several months if the desiccant was changed frequently. This method yielded a preparation of CAP which contained $96-98 \%$ of the expected proportion of phosphate, of which 96\% was acid labile. Moreover, urea, a by-product which interfered with colorimetric tests used, was barely detectable under the conditions used.

\section{METHODS}

Assays for OTC were carried out in centrifuge tubes in a total volume of $3.25 \mathrm{ml}$. The standard incubation mixture contained $20 \mu$ moles CAP, 20 $\mu$ moles ornithine, $500 \mu$ moles l'ris-acetate buffer, $\mathrm{pH} 9.0,{ }^{2}$ and a rate-limiting aliquot of the enzyme preparation. The reaction was allowed to proceed 5 min., after which $0.5 \mathrm{ml}$. of $2 M$ perchloric acid was added to precipitate protein. The tubes were chilled and centrifuged, and citrulline was measured in aliquots of the supernatants.

Citrulline was measured in two ways. For some experiments involving only the wild type enzyme, the method of Archibald was used (5). Because the OTC activity of the $s$ strain was so low, the more sensitive method of Koritz and Cohen (6) was used whenever comparisons of $s$ and wild type were made. It was found that the substrate, ornithine dihydrochloride, elevated the chromogenic value of citrulline, and this fact was taken advantage of by adding it in excess to all samples to be meas-

"Stock solutions were made by bringing 0.1 mole tris(hydroxymethyl)aminomethane ("Sigma 7-9," Sigma Chemical Co.) to $\mathrm{pH} 9.0$ with glacial acetic acid, und adjusting the volume to $100 \mathrm{ml}$. ured. It was later found that the chloride was the active substance (7), ornithine having no effect. The Koritz-Cohen reaction was modified somewhat as follows (Alice L. Tuttle, personal communication): To Klett-Summerson colorimeter tubes were added $1 \mathrm{ml}$. of the reaction mixtures, $1 \mathrm{ml}$. of a solution containing $40 \mu$ moles $\mathrm{Cl}^{-}$ion $/ \mathrm{ml}$., $4 \mathrm{ml}$. of $50 \%(\mathrm{v} / \mathrm{v})$ sulfuric acid, $0.2 \mathrm{ml}$. of $3 \%$ diacetylmonoxime, and $0.2 \mathrm{ml}$. of $0.4 \%$ sodium $p$-diphenylamine sulfonate. The procedure was the same as previously described from this point on, except for the addition of $0.2 \mathrm{ml}$. of $1 \%$ potassium persulfate in the final step instead of $0.25 \mathrm{ml}$. The tubes were measured in a Klett-Summerson colorimeter with a No. 54 filter. The method is sensitive to $0.01 \mu$ mole citrulline per tube, with an upper limit of approximately $0.10 \mu$ mole per tube under the conditions used. Where high activities were encountered, citrulline was measured in smaller aliquots of the original assay volume. The method allows measurement of reaction velocity under conditions where substrate concentration changes very little.

Protein was measured by the biuret method (8) or by the method of Lowry et al. (9). Specific activities are given as micromoles citrulline/mg. protein/hr

\section{Preparation of Partially Purified Ornithine Transcarbamylase FROM WILD TYPE AND \& Mrcelia}

For the purification of wild type OTC, $5 \mathrm{~g}$. acetone powder was suspended in $43 \mathrm{ml}$. of $0.05 M$ potassium phosphate buffer, $\mathrm{pH}$ 7.5. After standing $30 \mathrm{~min}$. at $0^{\circ}$, the suspension was centrifuged at $3500 \times g$ for $20 \mathrm{~min}$, and the supernatant was collected. The residue was resuspended in $30 \mathrm{ml}$. buffer and recentrifuged. To $50 \mathrm{ml}$. of the combincd cxtracts, $50 \mathrm{ml}$. ethanol $\left(-20^{\circ}\right)$ was added slowly with stirring, and the resulting precipitate was removed by centrifugation at $-10^{\circ}(3500 \times g$, $20 \mathrm{~min}$.). To the supernatant, $50 \mathrm{ml}$. ethanol was again added, and the precipitate was collected by centrifugation and resuspended in $50 \mathrm{ml}$. buffer. The materials which did not dissolve were removed without loss of OTC activity by centrifugation for $20 \mathrm{~min}$. at $24,000 \times g$ at $0^{\circ}$. Purification at this stage was 3.6 -fold, with a recovery of $73 \%$. To 50 $\mathrm{ml}$. of the second ethanol fraction, $15 \mathrm{~g}$. of solid ammonium sulfate was added, and dissolved. After 20 min., the precipitate was removed by centrifugation at $24,000 \times g$ for $20 \mathrm{~min}$. To the supernatant, $5 \mathrm{~g}$. more ammonium sulfate was added. The resulting precipitate was centrifuged out and collected in $25 \mathrm{ml}$. of $0.05 \mathrm{M}$ potassium phosphate buffer, $\mathrm{pH}$ 7.0. This fraction was dialyzed against $2000 \mathrm{ml}$. of the same buffer for $18 \mathrm{hr}$. with one 
change. The purification over the ethanol fraction was 6.7-fold; over the starting material, 24-fold. The over-all recovery was $66 \%$. The specific activity rose from 17.5 in the acetone powder extract to 420 in the dialyzed ammonium sulfate fraction. Assays throughout were followed by measuring citrulline by the method of Archibald (5).

For the purification of OTC from $s$, the KoritzCohen test for citrulline was used in all assays. Because this test is subject to much more interference than the Archibald test by materials in the extracts, certain departures in the method of purification given above are noted. Acetone powder, $2.5 \mathrm{~g}$., was suspended in $40 \mathrm{ml}$. of $0.05 \mathrm{M}$ phosphate buffer, $\mathrm{pH} 7.0$, centrifuged, and the residue re-extracted with $10 \mathrm{ml}$. more buffer. To $40 \mathrm{ml}$. of the combined extracts, $20 \mathrm{ml}$. ethanol was added, and the precipitate was removed by centrifugation. To the supernatant, $6.6 \mathrm{ml}$. ethanol was added, and the precipitate was again removed. To this supernatant, $13.4 \mathrm{ml}$. ethanol was added. The residue was collected, after centrifugation, in $30 \mathrm{ml}$. buffer, and $30 \mathrm{ml}$. more ethanol was added to the supernatant. This precipitate was also collected, after centrifugation, in $30 \mathrm{ml}$. buffer, combined with the previous fraction, and cleared by centrifugation. Purification at this stage was 2.1-fold; recovery was $85 \%$. To $60 \mathrm{ml}$. of the ethanol fraction, $18 \mathrm{~g}$. ammonium sulfate was added, the precipitate was removed, and $6 \mathrm{~g}$. more ammonium sulfate was added to the supernatant. This precipitate was collected, after centrifugation, in $10 \mathrm{ml}$. buffer and dialyzed. Purification was 10.5-fold in the ammonium sulfate step; over-all purification was 22 -fold, with a yield of $57 \%$. The specific activity rose from 0.47 to 10.5 at the end of the procedure.

Aspartate transcarbamylase (10), of normal activity in the starting materials, was not detectable in the purified OTC preparations from either strain. Purified preparations of both strains were stable for at least 3 months at $-20^{\circ}$.

\section{RESULTS}

\section{LOCALIZATION OF OTC IN Mycelial Extracts}

To test the association of OTC in either strain with cytoplasmic particles, and to determine whether the low OTC of $s$ was due to large losses in the usual methods of isolation, moist mycelial pads were suspended in a solution of $0.05 M \mathrm{~K}^{+}$potassium phosphate, $\mathrm{pH} \quad 7.0$, and $0.6 \quad M$ Dmannitol. The suspended mycelia were broken up with fine glass beads in a Nossal disintegrator, and the beads and cell debris were removed from the slurry by centrifugation at $1000 \times g$ for $5 \mathrm{~min}$. The supernatant was then centrifuged at 15,000 $\times g$ for $15 \mathrm{~min}$., and the residue was collected. The supernatant was recentrifuged at $100,000 \times g$ for $90 \mathrm{~min}$., and the residue and supernatant were collected. The lowand high-speed residues and the final supernatant were then tested for OTC activity. Regularly, $85 \%$ of the activity of wild type remained in the supernatant. In the case of $s$, the actvity was so low that it could not be measured accurately by the methods used. This indicates that the low OTC activity of $s$ is inherent in the strain itself, rather than in the method of OTC isolation. The similar stabilities of the OTC from $s$ and wild type to heat denaturation, mentioned below, also bear this out. In the same experiments, $95 \%$ of the aspartate transcarbamylase remained in the supernatant.

\section{Some Properties of OTC from Wild Type AND $s$}

Dialyzed crude extracts of acetone powders were used to test the effect of varying the time and the amount of extract upon the production of citrulline. Reasonable linearity of citrulline formation with both variables prevailed in the case of the two strains (Fig. 1). Citrulline was not produced to a detectable extent in the absence of enzyme, CAP, or ornithine, and OTC activity of both strains was destroyed by boiling the extracts for $5 \mathrm{~min}$.

Using dialyzed ammonium sulfate preparations, the dependence of citrulline production upon $\mathrm{pH}$ was measured. In this experiment, unbuffered reaction mixtures were used, because borate, carbonate, and glycine buffers inhibited both enzymes to varying degrees (Tris-acetate buffer was not inhibitory). To aliquots of the enzyme preparations, substrates adjusted to different $\mathrm{pH}$ 's with $1 \mathrm{~N} \mathrm{KOH}$ were added, and the assays were carried out as usual. The $\mathrm{pH}$ of duplicate reaction mixtures was measured to verify the $\mathrm{pH}$. The data (Fig. 2) show that the pII optimum of the reaction is approximately 9 when either $s$ or wild type preparations are used. CAP, which decomposes at pH's above 9 rather rapidly, 

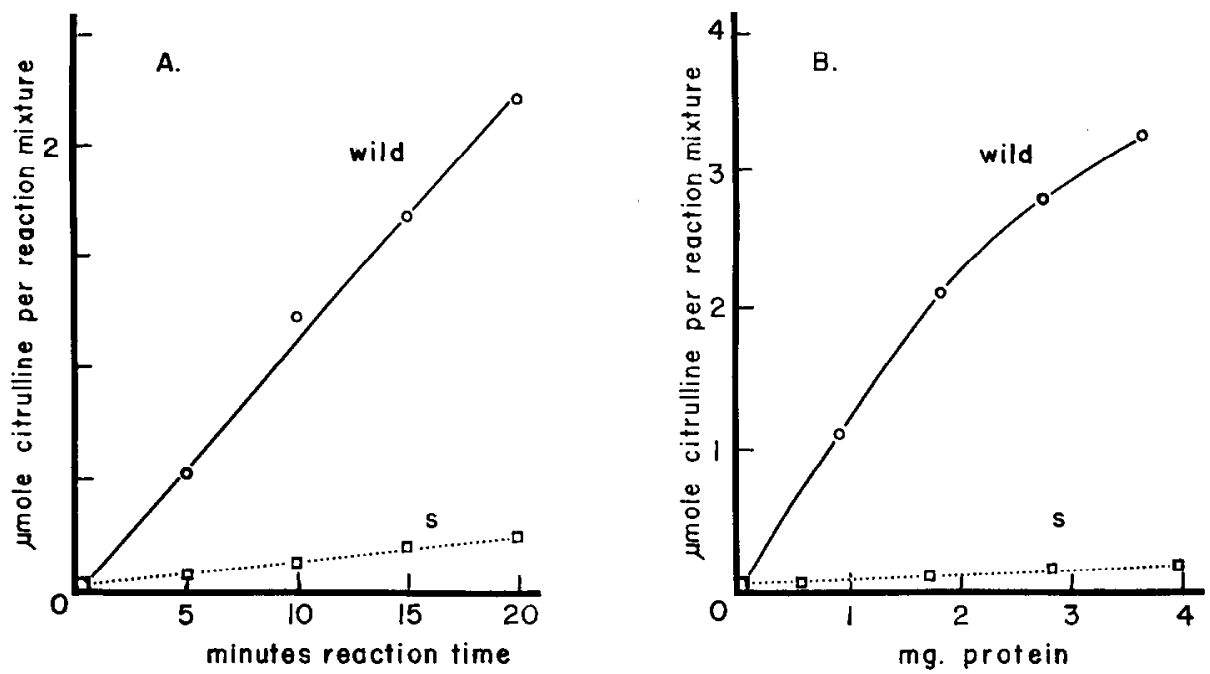

Fig. 1. Relationship of citrulline formation with time $(A)$ and with the amount of protein in reaction mixtures $(B)$, using crude dialyzed extracts of the wild type and $s$ strains. In $(A)$, the amounts of protein used per $3.25-\mathrm{ml}$. reaction mixture were for wild type, $0.46 \mathrm{mg}$., for $s, 2.85 \mathrm{mg}$. In $(B), 5$-min. reaction times were used.

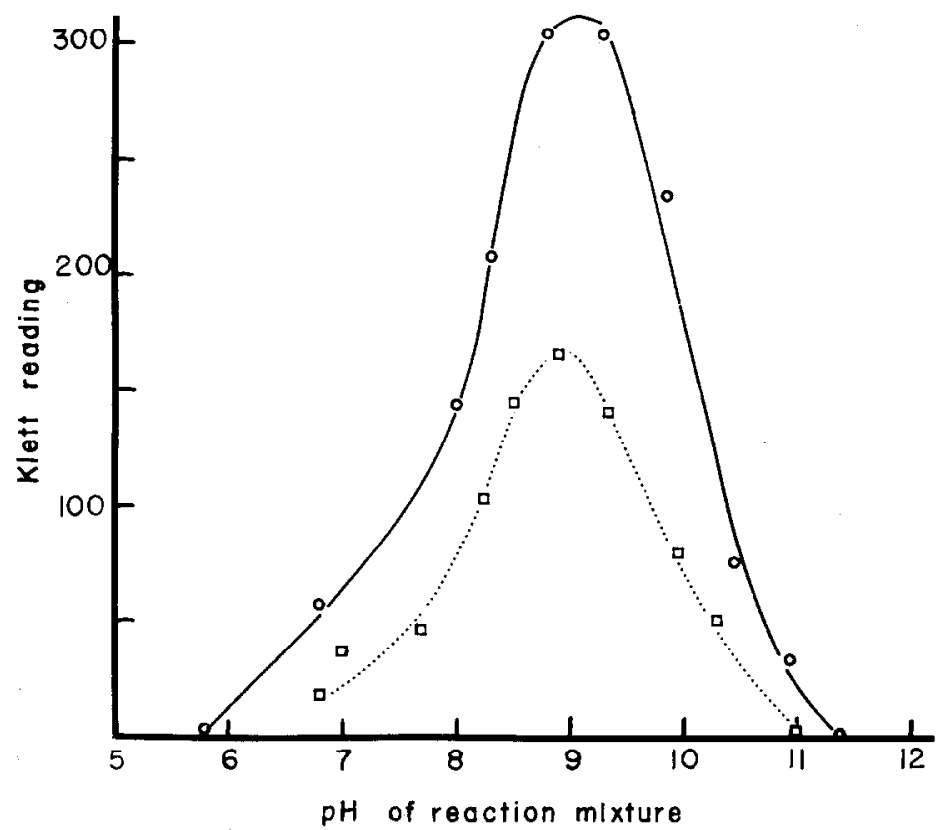

Frg. 2. Relationship of OTC activity with the $\mathrm{pH}$ of unbuffered reaction mixtures, using partially purified wild type (solid curve) and $s$ (dotted curve) extracts. The extracts were adjusted to the same order of activity in this experiment, and citrulline was measured in the same manner in the case of both strains.

was still unlimiting at the end of the reaction, and the primary decomposition product of CAP, cyanate, is not inhibitory to the reaction in concentrations of 20 $\mu$ moles per reaction mixture.
The dependence of the OTC reaction upon ornithine concentration, using the two types of preparations, is shown in Fig. 3 by means of a Lineweaver-Burk plot. The affinity of the wild type enzyme for this 


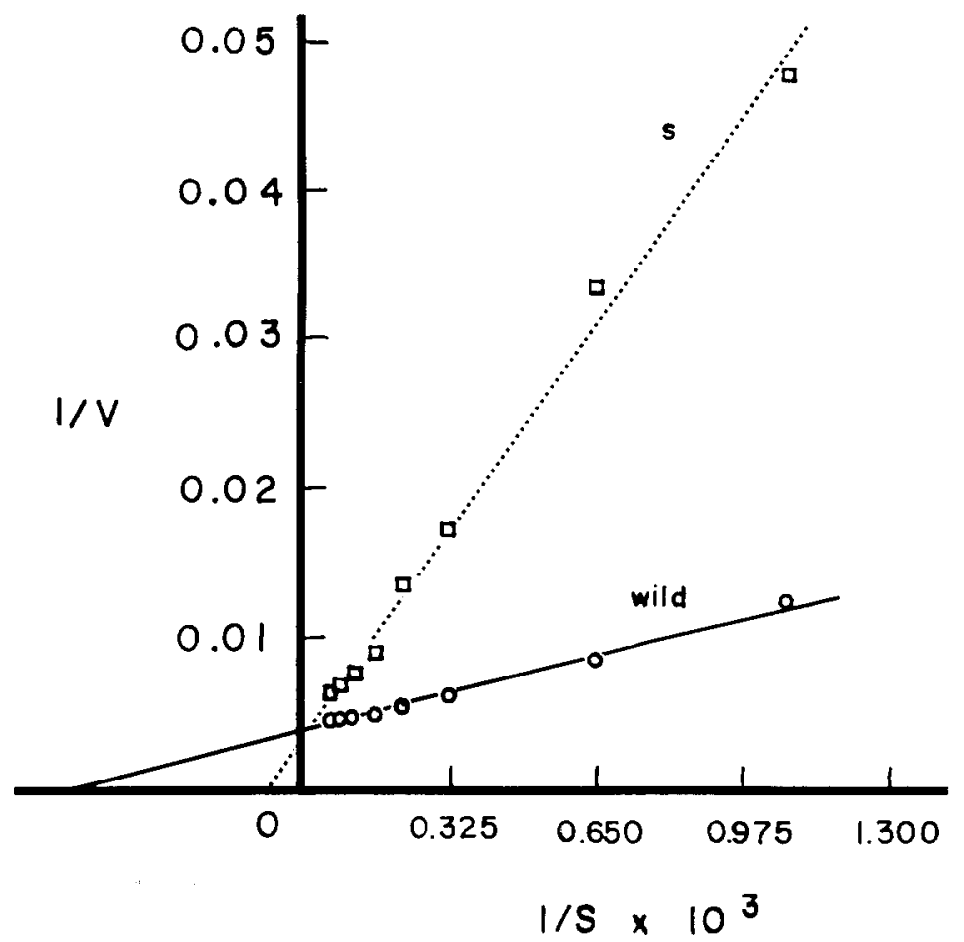

FIG. 3. Lineweaver-Burk plots of the relationship of reaction velocity versus ornithine concentration, using OTC of wild type and $s$. The lines were fitted by eye, and $K_{m}$ values (see text) were calculated from the $X$ intercepts.

substrate is greater than that of $s$, as indicated by the positions of the $X$ intercepts. The $K_{m}$ values derived graphically from such plots are, for wild type, $1.9 \times 10^{-3} \mathrm{M}$; for $s$, approximately $14 \times 10^{-3} M$ with some variation (from 10 to $15 \times 10^{-3} \mathrm{M}$ ) in the latter from experiment to experiment. The difference between the two struins is clear, however, even in crude dialyzed extracts, and the constants have the same general values.

The dependence of the reaction on CAP concentration was vastly different in the case of the two preparations. The substratevelocity curves are shown in Fig. 4; a Lineweaver-Burk plot of the data involving the wild type enzyme is also shown. It appears that the OTC of $s$ is saturated at a much lower concentration of CAP than is that of wild type. The $K_{m}$ of the wild type for CAP is approximately $3 \times 10^{-4} M$. Measurements of the constant of the $s$ enzyme are impossible with the methods used, because the reaction is limited only by the amount of CAP, rather than its concentra- tion, at the lower limit, and the enzyme is completely saturated at slightly higher points. A more rigorous test of the conditions affecting the relationship between the OTC activity of $s$ and CAP concentration was made by varying the concentration of ornithine and the amount of enzyme, using an independently purified OTC preparation. The use of $40 \mu$ moles ornithine raises the level of the plateau by approximately the amount expected $(20 \mu$ moles per reaction mixture, used in the first experiment, is not saturating for the $s$ enzyme), and doubling the concentration of enzyme elevates the plateau by a factor of two. The lowest point in all cases (at $0.05 \mu$ mule CAP per reaction mixture) remains the same within experimental error, however, and indicates a total conversion of the CAP present to citrulline during the time of the assay (Fig. 5).

The activity of the wild type and $s$ preparations was additive in mixed reactions, both in purified and crude preparations. In one experiment, the wild type preparation 


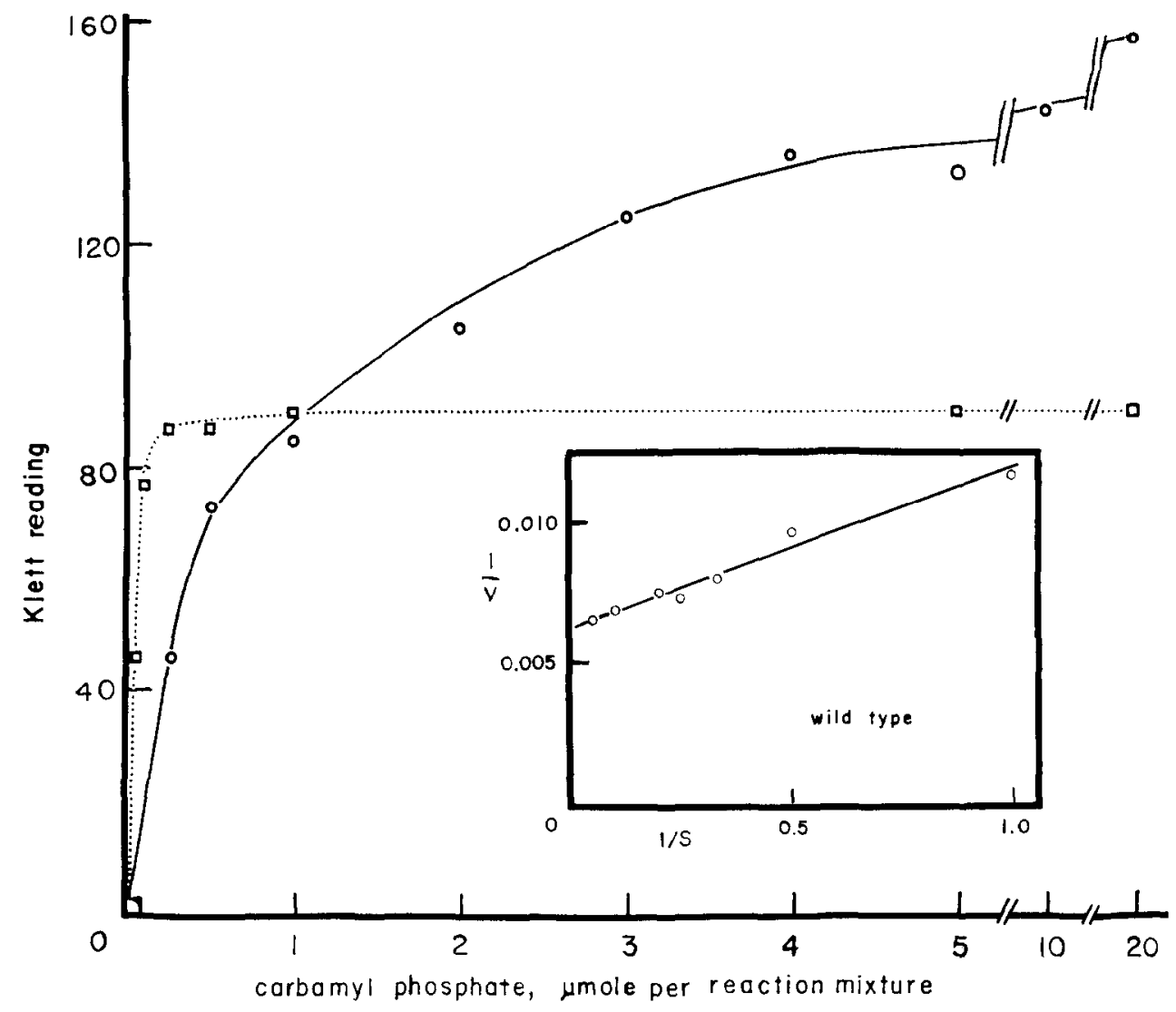

FIg. 4. Relationship of reaction velocity with CAP concentration, using OTC of wild type (solid curve) and $s$ (dotted curve). The inset shows a Lineweaver-Burk plot of the wild type data. Such a plot is not appropriate for the $s$ enzyme, because at no point is the reaction limited by CAP concentration (see text).

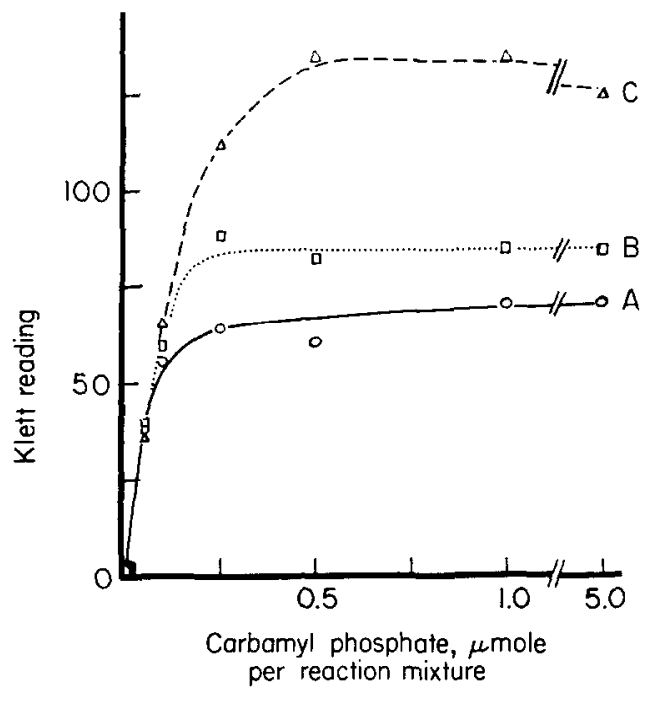

gave $0.20 \mu$ mole citrulline, the $s$ preparation $0.10 \mu$ mole, and a reaction mixture containing both enzymes in the previously tested amounts gave $0.31 \mu$ mole. These results indicate that the low activity of $s$ is not due to a free inhibitor, a compctitive reaction, or the lack of a cofactor.

The OTC activity of both wild type and $s$ strains, using purified samples of similar

FIG. 5. Relationship of $s$ OTC activity with CAP concentration. Curve $A: 0.1 \mathrm{ml}$. enzyme extract, 20 moles ornithine per reaction mixture. Curve $B: 0.1 \mathrm{ml}$. enzyme extract, $40 \mu$ moles ornithine per reaction mixture. Curve $C: 0.2 \mathrm{ml}$. enzyme extract, $20 \mu$ moles ornithine per reaction mixture. Scale: $0.05 \mu$ mole citrulline per reaction mixture $=37$ Klett units. 
activity, and which were made equal in protein concentration by the addition of bovine serum albumin to the wild type preparation, was stable to heating at $70^{\circ}$ for 30 min., was inactivated in $30 \mathrm{~min}$. at $\mathbf{7 4 ^ { \circ }}$, and in less than $3 \mathrm{~min}$. at $79^{\circ}$. All experiments were carried out in $0.05 M \mathrm{~K}^{+}$phosphate buffer, $\mathrm{pH}$ 7.0. The data are not sufficiently refined to detect any small differences in inactivation rates, if any exist.

\section{DISCUSSION}

It has been shown that OTC isolated from wild type and from the $s$ strain is similar in its response to purification procedure, $\mathrm{pH}$ of the reaction mixture, and heat inactivation. The enzymes from the two sources are different in their dependence on the concentration of both substrates of the reaction, a finding which strongly suggest that the $s$ locus controls the primary structure of OTC. The existence of mutations allelic to $s$ which lead to a complete deficiency of OTC would lend this conclusion more force, but no other mutations have been observed at any locus to date which have a significant effect on this enzyme $(3,11)$. It is therefore also possible that there are two species of OTC normally present in Neurospora and that the $s$ mutation eliminates the one present in highest activity. The data on the wild type preparation presented here are not sufficient to rule out this jossibility. The existence of quasi-duplicate genetic loci could explain the difficulty in finding strains completely deficient in OTC by the usual selection procedure.

The difference in the response of the two enzymes to ornithine concentration is probably not a crucial one biologically. In strains carrying $s$, the lowered rate of ornithine utilization would be expected to cause an elevation of the concentration of this substrate or its precursor, glutamic- $\gamma$ semialdehyde, to less limiting or to unlimiting levels. Preliminary electrophoresis patterns of the basic amino acids bear this out.

Although the affinity of the OTC of $s$ for CAP eannot be measured directly, the fact that the cnzyme is saturated at less than $1.5 \times 10^{-4} M$ indicates that it has significantly greater affinity than the OTC of wild type $\left(K_{m}=3 \times 10^{-4} M\right)$. Assuming that OTC activity in wild type is not present in more than 40 -fold excess of limiting concentration (for growth), the ligh affinity of the OTC of $s$ for CAP may compensate in vivo to a large extent for its low activity.

\section{REFERENCES}

1. Mitchell, M. B., and Mitchell, H. K., Proc. Natl. Acad. Sci. U. S. 38, 205 (1952).

2. Davis, R. H., Science 131, 470 (1961).

3. Davis, R. H., Gene'tics 47, in press (1962).

4. Spector, L., Jones, M. E., and Lipmank, F., in "Methods in Enzymology" (S. P. Colowick and N. O. Kaplan, eds.), Vol. III, p. 653. Academic Press, New York, 1955.

5. Anchibald, R. M., J. Biol. Chem. 156, 121 (1944).

6. Koritz, S. B., Axd Coher, P. P., J. Biol. Chem. 209, 145 (1954).

7. Crokaert, R., Axo Schram, F., Bull. soc. chim. biol. 40, 1093 (1958).

8. Laỹe, E., in "Methods in Enzymology" (S. P. Colowick and N. O. Kaplan, eds.), Vol. III, p. 447. Academic: Press, New York, 1955

9. Lowry, O. H., Rosebrocgh, N. J., Farr, A. L., and Raxdall, R. J., J. Biol. Chem. 193, 265 (1951).

10. Davis, R. H., Proc. Natl. Acad. Sci. U. S. 46, 677 (1960).

11. Fincham, J. R. S., Advances in Enzymol. 22, 1 (1960). 